\title{
Implementation of IoT in Embedded Systems for Real Time Water Quality Monitoring
}

\author{
Ravikumar Kondle, S. Dastagiri, M. V. Lakshmaiah
}

\begin{abstract}
Here we describe an embedded system, its development and design with the help of Raspberry Pi 3 controller that monitors the quality parameters of water which are $\mathrm{pH}$ level, turbidity, conductivity, total dissolved solids (TDS) and temperature at the same time. Internet of Things (IoT) technique is employed for the development of the system. Using this system, we have collected the data for the quality of water parameters include: $\mathbf{p H}$ level, turbidity, electrical conductivity, total dissolved solids (TDS) and temperature. After processing the data, a short message and email is sent using GSM/GPRS module when the parameters exceed the accepted limit. The efficiency of the system has been checked by comparing the parameter values that are collected using this system with manually measured parameter values in a certified laboratory.
\end{abstract}

Keywords: Accuracy, IoT, Raspberry pi, Sensor Network, Water Quality.

\section{INTRODUCTION}

Monitoring of quality of water is important to check whether the water from the resources is potable or not. Because of rapid increase in industrialization and urbanization, the natural water is contaminated. Every person deserves unpolluted water to be healthy. So it is required to check the quality of water by measuring the basic water parameters like $\mathrm{pH}$, Turbidity, etc.[2] This monitoring also helps the government to continuously assess the water pollution level and take the essential measures in reduce/control it.

Earlier measurement of the quality of water was done by traditional methods which involve collecting the samples of water manually at different locations and analyse them in laboratories. There are certain limitations for earlier methods, namely,

i. Time consumption

ii. Poor spatiotemporal coverage

iii. Capital intensive /labour intensive and

iv. Lack of real time monitoring.

Revised Manuscript Received on March 18, 2020.

* Correspondence Author

Ravikumar Kondle, Research Scholar, Department of Physics, Rayalaseema University, Kurnool, Andhra Pradesh, India.

2) Asst.Prof, St. Peter's Engineering College, Hyderabad, Telangana, India Email: ravionline88@gmail.com.

S.Dastagir, Research Scholar, Department of Physics, Sri Krishnadevaraya University, Ananthapur, Andhra Pradesh, India. Email: giri22522@gmail.com

Prof. M.V. Lakshmaiah, Professor, Department of Physics, Sri Krishnadevaraya University, Ananthapur, Andhra Pradesh, India

Email: Drmv12009@gmail.com
Due to lack of real time monitoring, it is difficult to alert the people immediately about the exceeding of the quality of water parameters. Therefore in order to check the quality of water modern methods of continuous surveillance have been adopted [1].These are based on embedded systems using GSM (Global System for mobile communication), IoT. [3] GSM based systems: These systems consist of sensors to measure turbidity, $\mathrm{pH}$, temperature, electrical conductivity, a micro controller, data acquisition modules, module for data processing and transmission. These sensors automatically and continuously give the measurements of the water quality. The micro controller collects the data and then processes and analyses it. The report of the analysis is sent in the form of a short messaging service (SMS) through GSM network. IoT based Systems: This system contains sensors, microcontroller, and actuators. The data is then processed and analysed by the micro controller. This data is intern sent to server using internet modules (WIFI network, GPRS). [4] This data can be retrieved from any part of the world.

Here, we have designed and developed an IoT based embedded system for continuous assessment of water quality; by this the limitations of traditional methods can be surpassed. The arrangement of contents of this paper is: First we elucidate the design and the working method of the system. Next, we present and discuss the results. At the end, we summarize our results.

\section{PROPOSED SYSTEM}

This system has been provided with Raspberry Pi 3 Micro controller which has an effective ARM Cortex-A53 which is Quad Core processor with clock speed 1.2GHz. The Cortex-A53 is a 64-bit processor. It works with Linux/Raspbian operating system. This processor has many enhancements like low power, high efficiency, huge RAM, more clock speed, multi-tasking, extensive feature set for broad application support, etc. The Figure1.shows the whole system's block diagram.

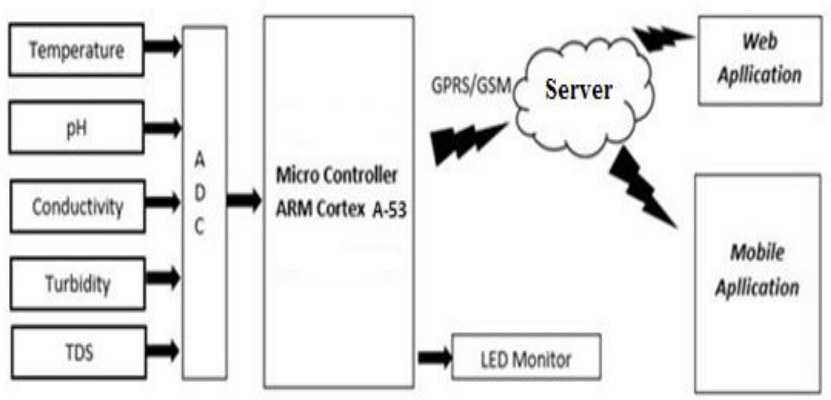

Fig.1.Block diagram of the proposed system 
The core controller is connected to the different sensors to measure $\mathrm{pH}$, turbidity, temperature, electrical conductivity and TDS of water through an analog-digital converter. The system has MC3208 ADC converter with 12 bit resolution, eight input channels. Which supports the SPI (Serial Peripheral Interface) for faster communication in the shorter distance.

The analog channel 0 of MSP3208 ADC is connected to the temperature sensor, which is sensing the thermal energy and converting it into electrical voltage. The analog channel 1 of $\mathrm{ADC}$ is connected with the $\mathrm{pH}$ sensor through the Operational Amplifier. The $\mathrm{pH}$ sensor measures the potentiality of hydrogen ions in the water. The analog channel 2 is connected the turbidity sensor. The analog channel 3 is now connected to the to the conductivity sensor with an operational amplifier. Later the 12 bit Serial ADC output is connected to the micro controller. The core controller accesses the data and processes it, further sends to server using internet. This data can be taken from anywhere at any time using webpage or mobile application. While processing the data, if the system finds any of the quality parameters exceeds the allowed limit, an alert SMS and email will be sent using GSM/GPRS module. [6].

\section{RESULTS AND DISCUSSION}

This system is tested at St. Peter's Engineering College (17.5659oN, $78.4512 \mathrm{o}$ E) located (Fig.2) 3-4 km away from Jeedimetla Industrial Region, in Hyderabad, a city of Telangana state in India. Industrial Development Area, Jeedimetla, is the biggest industrial estate in Asia. Machine tools, pharmaceuticals, electric appliances, textiles and chemicals industries are important industries located here. The system is used to quantify the impact of these industries on water quality in surrounding areas. The system is evaluated by comparing the water quality parameters tested in a certified chemical St. Peter's Engineering College is located among these areas. The water quality at this location is measured using the proposed equipment. We found the values for the aforementioned parameters for describing the quality.

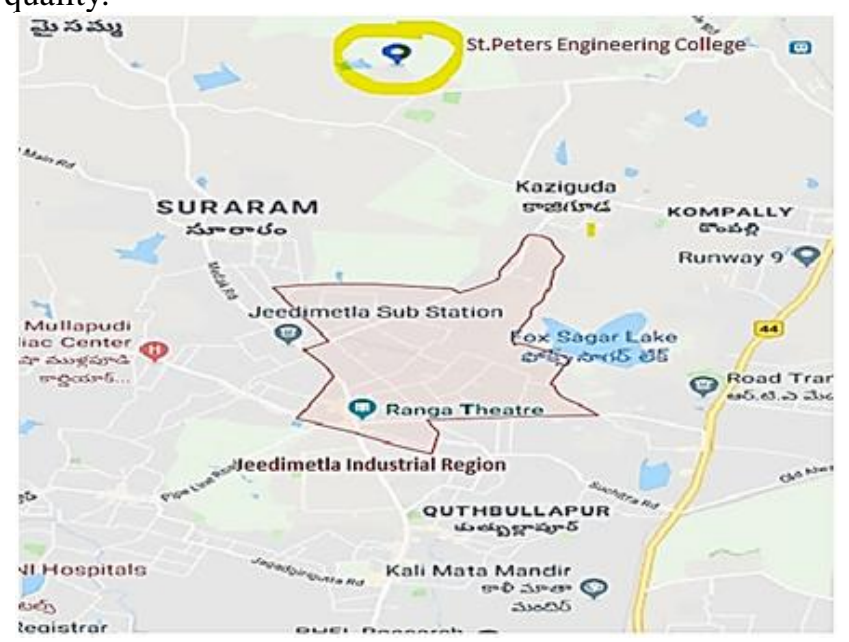

Fig.2. Location of the system where it is equipped.

A) pH Level
The numeric representation of gram-equivalent per litre of hydrogen ion concentration is $\mathrm{pH}$ in any solution. It varies from 0 to14. The $\mathrm{pH}$ level of water indicates that water is whether acidic/non acidic or neutral. If $\mathrm{pH}$ level is 7 , water is neutral and good for drinking and for other purposes. To measure $\mathrm{pH}$ level, we immersed the electrodes of

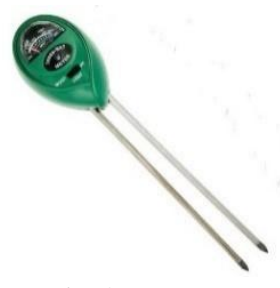

Fig.3.ph sensor PHE-45P sensor in water. It sends the analogue data to the ADC then to controller. As we mentioned earlier, the controller process it and sends data to cloud storage. If $\mathrm{pH}$ level is hazardous, an alert signal is sent. Image of $\mathrm{pH}$ sensor is shown fig 3 . We found out that the $\mathrm{pH}$ value of the sample water is 7.1( 0.5) and it is in within the limit.

\section{B) Turbidity}

Water samples light scattering property is referred as turbidity.

It is described as haziness caused by constituent particle in the water. Turbidity can be caused by soil erosion, waste discharge, urban runoff, algae growth etc. The unit of turbidity is Nephelometric Turbidity Unit (NTU). According to Bureau of Indian Standards, the acceptable

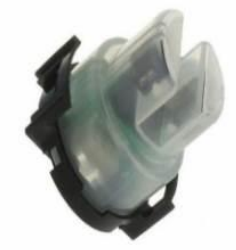

Fig. 4.Turbidity Sensor limit of turbidity is 1 NTU.

To measure this parameter, TSD 10 sensor is immersed in water. This sensor consists of a photo transistor and a photo diode. Light rays (IR) emitted from photo transistor pass through the water sample and reach the photo diode. If any suspended particles exist, the light rays can get scattered by colliding them. As a result, the amplitude of the light rays at diode is less than the emitted rays. The turbidity is evolved from the difference between the density of light sent and received by the micro controller that operates the sensors. The observed water sample turbidity is 0.1 NTU which is ideal for drinking water.

\section{C) Electrical Conductivity}

Electrical conductivity (EC) is dissolve material measurement in water, which has the ability to pass electrical current through them. Conductivity can be said as a capability of water to permit the flow of electricity through it. Water gets the ability to permit the electricity to pass through owing to the ions concentration in it. The ions in water are the result of the dissolved salts and inorganic materials. They are alkalis, chlorides, sulphides, and carbonate compounds A conductivity Sensor is placed between the probe electrode and reference electrode. When the water comes into contact with the tip of the electrode, the sense electrode and reference electrode get connected. This current is sensed, amplified and made to send to controller. Electrical conductivity unit is
Fig .5. Eectrical Conductivity Sensor 
micro Siemens $(\mu \mathrm{S})$. The limit of electrical conductivity is around $500 \mu \mathrm{S}(0.005 \mathrm{~S})$.Distilled water has got a very less electrical conductivity as a number of ions is less.

We observed that electric conductivity of the sample water is $311.6 \mu \mathrm{S} / \mathrm{cm}$. Which indicates the absence of harmful materials

\section{D) Total dissolved solids (TDS) Sensor.}

TDS is the proportion of the disintegrated consolidated substance of all inorganic and natural substances present in water in different forms. TDS is utilized as a sign of taste of water. TDS shows the presence of chemical contaminants in water.

TDS is measured in ppm (parts per million) or in $\mathrm{mg} / \mathrm{l}$. The

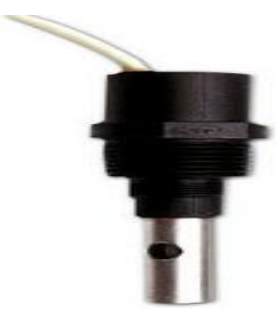

Fig .6.TDS sensor acceptable limit of TDS is $500 \mathrm{ppm}$. . We observe that the TDS value of the sample water is within the limit and as low as $161(\sim 2)$.

\section{E) Temperature sensor}

This sensor measures the temperature of the water. Temperature Sensor (LM35) is a precisely integrated circuit, whose voltage output is shown in centigrade temperature. Measurement of the temperature is very important as the above mentioned water quality parameters are temperature dependent.

The LM35 temperature sensor is utilized to identify the exact temperature in centigrade. The results shown by this sensor depicts the linearity of water. The output voltage of this IC sensor is linearly relative to the Celsius temperature. It can work in ranges from $-55^{\circ}$ to $+150^{\circ} \mathrm{C}$. This works from 4 to 30 volt. Temperature sensor circuit has terminals such as two inputs like non-inverting (+) and inverting (-) and only one output pin. We observe that the temperature value of the sample water is $26^{\circ} \mathrm{C}$.

Table.I. Observed values of water quality parameters by the system.

\begin{tabular}{|l|c|l|l|l|l|l|}
\hline \multirow{2}{*}{$\begin{array}{c}\text { S. } \\
\text { No. }\end{array}$} & \multicolumn{6}{|c|}{ Water quality parameters by the system. } \\
\cline { 2 - 7 } & Date & $\begin{array}{c}\text { Temper } \\
\text { ature }\left(^{\circ} \mathrm{C}\right. \\
)\end{array}$ & $\boldsymbol{p H}$ & $\begin{array}{c}\text { Turbi } \\
\text { dity }\end{array}$ & $\begin{array}{c}\text { Conduc } \\
\text { tivity } \\
(\boldsymbol{\mu S} / \text { cm })\end{array}$ & $\begin{array}{c}\text { TDS } \\
(P p m)\end{array}$ \\
\hline 1 & $2019-02-06$ & 026 & 07 & 0.4 & 231 & 161 \\
\hline 2 & $2019-02-06$ & 026 & 06 & 0.6 & 228 & 159 \\
\hline 3 & $2019-02-06$ & 026 & 07 & 01 & 233 & 163 \\
\hline 4 & $2019-02-06$ & 026 & 07 & 01 & 238 & 166 \\
\hline
\end{tabular}

The accuracy of laboratory and the observed values of the parameters by system are tabulated in Table 2 .
Table.2. Evaluation of Accuracy.

\begin{tabular}{|l|c|l|l|l|l|}
\hline & & $\begin{array}{c}\text { Measured } \\
\text { Values by } \\
\text { the System } \\
\text { S.No. }\end{array}$ & $\begin{array}{c}\text { Measured } \\
\text { Values in } \\
\text { the Lab } \\
(P L)\end{array}$ & $\begin{array}{c}\text { Difference } \\
\left(P_{S} \sim P_{L}\right)\end{array}$ & Accuracy \\
$(\%)$
\end{tabular}

Accuracy $=$ Measured parameter value by System Measured parameter value in Lab

Percent accuracy $=\left(\mathrm{P}_{\mathrm{s}}-\mathrm{P}_{\mathrm{L}} / \mathrm{P}_{\mathrm{L}}\right) \mathrm{X} 100$

\section{CONCLUSIONS}

We have designed and developed an embedded system to monitor the water quality continuously. We have used Raspberry Pi 3 as a controller of the system. We have used this system to check the water quality of one of the biggest industrial regions of Telangana state, India. We have compared values measured by the system against the results obtained by a certified lab and the results are in good agreement, and as such the system designed and developed by us is no way inferior. This is a good indication that this system can be used to test the quality of water anywhere. Also we can extend this study to evaluate the temperature influence on the quality of the water by collecting the data from different remote locations/areas.

\section{REFERENCES}

1. Lambrou, Theofanis P., et al. "A low-cost sensor network for real-time monitoring and contamination detection in drinking water distribution systems." IEEE sensors journal 14.8.1 (2014): 2865-2872.

2. Ramanaiah SV, et al.."Monitoring of fluoride concentration in ground water of Prakasham District in India: correlation with physico-chemical parameters." J Environ Sci ng. 2015Apr;48(2):12-18

3. Alessio B, Walter D, Valerio P, Antonio P (2015) Integration of Cloud computing and Internet of Things: A survey FuturGenerComputSyst 56:684-700

4. Al-Fuqaha A et al (2015) Internet of Things: A Survey on Enabling Technologies, Protocols, and Applications. IEEE CommunSurv Tutorials 17(4):2347-2376.

5. Azedine C, Antoine G, Patrick B, Michel M (2000) Water quality monitoring using a smart sensing system. Measurement: 211-218.

6. Bhatt Jayti, JigneshPatoliya (2016), "IoT based water quality monitoring system", In: Proc of 49th IRF IntConf, 21 Feb 2016

7. Biljana L, Risteska S, Kire VT (2017) A review of Internet of Things for smart home: Challenges and solutions. J Clean Prod 140(3):454-464.

8. Central Ground Water Board (2017) Ministry of Water Resources, River Development and Ganga Rejuvenation, Government of India. http://cgwb.gov.in/. Accessed 21 July 2017

9. Christie R, Mallory C, Jared L, Alan M (2014) Remote Delay Tolerant Water Quality Monitoring. In: IEEE global humanitarian technology conference, $10-13$ Oct 2014

10. Francesco A, Filippo A, Carlo GC, Anna ML (2015) A Smart Sensor Network for Sea Water Quality

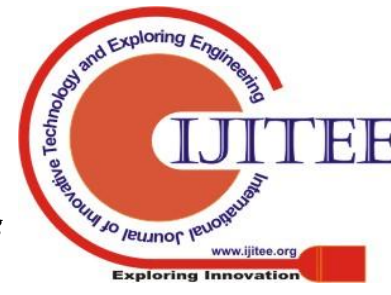


Monitoring. IEEE Sensors J 15(5):2524-2532

11. Jianhua D, Guoyin W, Huyong Y, Ji X, Xuerui Z (2015) A survey of smart water quality monitoring system. Environ SciPollut Res 22(7):4893-4906

12. Li Z, Wang K, Liu B (2013) Sensor-Network based Intelligent Water Quality Monitoring and Control. Int J Adv Res ComputEngg Tech 2(4):1659-1662

13. Mitar S, Goran M, Libu M, Krzystof Z (2016) Multi-sensor system for remote environmental (air and water) quality monitoring. In: 24th telecommunications forum, 22-23 Nov. 2016.

14. Muinul H, Syed I, Alex F, Homayoun N, Rehan S, Manuel R, Mina H (2014) Online Drinking Water Quality Monitoring: Review on Available and Emerging Technologies. Crit Rev EnvSci Tech 44(12):1380-1431

15. Niel AC, Reza M, Lakshmi N (2016) Design of Smart Sensors for Real-Time Water Quality Monitoring. J IEEE Access 4:3875-3890

16. Offiong N, Abdullahi S, Chile B, Raji H, Nweze N (2014) Real Time Monitoring Of Urban Water Systems for Developing Countries. IOSR J Comput Eng 16(3):111-114

17. Pandian DR, Mala K (2015) Smart Device to monitor water quality to avoid pollution in IoT environment. Int $\mathrm{J}$ Emerging Tech ComputSci Electron 12(2):120-125.

18. Peng J, Hongbo X, Zhiye H, Zheming W (2009) Design of a Water Environment Monitoring System Based on Wireless Sensor Networks. J Sensors 9:641-643.

19. Sathish K, Sarojini M, Pandu R (2016) IoT based real time monitoring of water quality. Int J Prof Eng Stud VIII(5):1201-1205

20. Vijayakumarn N, Ramya R (2015) The real time monitoring of water quality in IoT environment. In: international conference on circuits, power and computing technologies, 19-20 March 2015.

21. Parhana, P \& Lakshmaiah, Mv \& Allahudheen, Shaik \& . S, Dastagiri \& Saritha, Vijaya. (2017). Review on Internet of Things: Recent Applications and its Challenges.

\section{AUTHORS PROFILE}

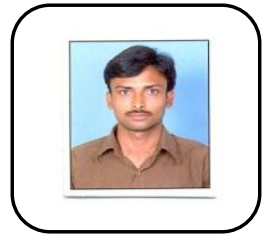

Ravikumar Kondle received his M.Sc. (Physics) degree in 2005 from Osmania University, Hyderabad. $\mathrm{He}$ is a Research Scholar, Department of Physics, Rayalaseema University, Kurnool. He was published two research articles in refereed journals. Attended, two conferences for present his research work. His Research interests focus on design and development of applications in Physics. Embedded Systems, Wireless sensor networks, their

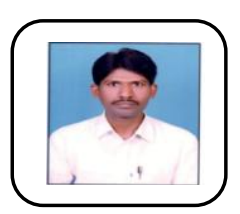

S Dastagiri received his B.Ed degrees in 2007 and M.Sc (Physics) in 2012 from Rayalaseema University, Kurnool. A research Scholar, Department of Physics. Sri Krishnadevaraya University, Anantapur, $\mathrm{He}$ was published 7 research articles in refereed journals. Attended, 2 international, 5 National conferences, 10 National seminars, 5 workshops for present his research work. His Research interests focus on preparation and characterization of nanomaterial, he was studied electrical/optical, structural, surface morphological and a thermal property of the nanomaterial at varies applications.

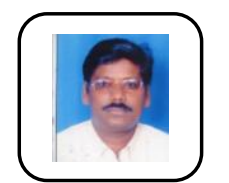

Prof. M. V. Lakshmaiah received the M.Sc., M.Phil. and Ph.D. degrees from Sri Krishnadevaraya University, and visiting professor in USA-2008. He is presently BoS Professor in the Department of Physics and Head in Department of Electronics, Sri Krishnadevaraya University, Anantapur, Andhra Pradesh, India. Prof. M. V. Lakshmaiah has published more than 70 articles in referred journals, and has attended number of national/international conferences to present his research work. He was awarded $11 \mathrm{Ph} . \mathrm{D}$.'s and 4 M.Phil.'s to their research students and 6 research students are pursuing Ph.D. under the guidance of Prof. M. V. Lakshmaiah. His most experienced in academic events also, and finally his current research interests are material science and electronics. 